\title{
Construction and Practice of Experimental Teaching System of New Engineering Specialty Based on CDIO Mode
}

\author{
Jiangtao Wang \\ College of Network Communication, Zhejiang Yuexiu University, Shaoxing, China \\ Email address: \\ 3068525606@qq.com \\ To cite this article: \\ Jiangtao Wang. Construction and Practice of Experimental Teaching System of New Engineering Specialty Based on CDIO Mode. Higher \\ Education Research. Vol. 6, No. 1, 2021, pp. 20-26. doi: 10.11648/j.her.20210601.13
}

Received: February 20, 2021; Accepted: March 4, 2021; Published: March 12, 2021

\begin{abstract}
In the process of "internationalization" of higher education, especially engineering majors pay attention to the cultivation of engineering practice ability and innovation ability. The concept of the CDIO model is very consistent with the goal of internationalization of talent training. The construction and practice of the CDIO-based experimental teaching system can well inherit and innovate the CDIO concept, strengthen the openness and innovation of students' thinking, and focus on innovation ability, professional core competence, and communication Cultivation of the ability to express and teamwork and improve the internationalization of talents. Pay attention to the development of experimental teaching in the implementation process of professional talent training, build laboratory implementation based on the concept of "experimental reuse", and pay attention to integrating the second-level project and the first-level project when constructing the experimental curriculum system to achieve nesting between projects Sexuality, forming mutual support, embodies the "modular" design of the laboratory. Whether it is the construction of the experimental management system or the implementation of the laboratory, the course system is ultimately required to be implemented. According to the connotation of digital engineering, combined with the concept of CDIO engineering, taking industrial digitalization and digital industrialization as the direction, adhere to the cultivation of CDIO core literacy training, and build "intelligence" Media Technology Curriculum Framework System".
\end{abstract}

Keywords: CDIO Model, Digital Media Technology, Laboratory Group, Project-driven

\section{Introduction}

In the development of higher education, with the improvement of the degree of "internationalization", especially the training of engineering talents has an increasingly strong demand for engineering practice ability and innovation ability [1]. For engineering application-oriented majors, with strong practicality, the curriculum system design focuses on the organic combination of experimental teaching and theoretical teaching. Compared with theoretical teaching, experimental teaching is more intuitive and more direct for students' innovative ability training. Experimental teaching cannot simply be understood as an aid to theoretical teaching. The relationship with theoretical teaching is like the "two legs" of human beings, supporting each other, and can deeply integrate knowledge and practice.

In the process of cultivating high-level applied talents [2], the integration of the CDIO model and the experimental teaching system is a major reform in the construction of the experimental teaching system. It reflects the project-driven idea. The real engineering experimental environment is transplanted into the curriculum, and in the experimental teaching Complete CDIO core competence training. Therefore, this article attempts to combine the CDIO engineering education model [3], with the construction of the experimental teaching system of the data visualization course group as the starting point, and conduct the construction practice and discussion of the experimental curriculum system.

\subsection{International Development Situations}

One of the major achievements of the international 
engineering education reform is the CDIO engineering education model. In 2010, its founder, Edward Crawley, won the "Gordon Award" of the American Academy of Engineering for this reason, which is called the "Nobel Prize in Engineering". If the CDIO model is the embodiment of the precipitation in the field of engineering education reform in developed countries in Europe and America for more than two decades, then the operability of the 12 standards involved in the CDIO system reflects the strong vitality of the CDIO model. The Swedish National Agency for Higher Education (Swedish National Agency for Higher Education) used CDIO standards to evaluate 100 domestic engineering degrees and found that it is more suitable for the systematic development of engineering education than the original standards. So far, dozens of world-famous universities have joined the CDIO organization, especially for engineering majors to fully promote the CDIO engineering education concepts and standards, and the talent output is well received by the academic community and the industry.

The CDIO model emphasizes the construction of engineering education based on the background of the "conception-design-implementation-operation" process of real-world products and systems, designing the professional quality system of engineers, and clarifying the direction of engineering education reform. CDIO standards run through the entire process of engineering education implementation, can comprehensively guide engineering education reforms, reflect scientific and advanced nature, and represent the future of contemporary engineering education.

\subsection{Development Situations in China}

There are a series of problems in my country's engineering education practice. For example, under the current assessment and evaluation system, professors with outstanding theoretical achievements have the right to speak in the talent training process, and the technical backbone of the industry has extremely low participation in the talent training process, resulting in greater personal academic abilities. The more important teamwork and skill innovation ability training in education [4] is seriously missing. According to relevant statistics, the degree of internationalization of engineering and technical talents in my country is low, the education process is too focused on theory, lack of collaboration ability, and the ability to solve practical problems as a team is seriously lacking.

In 2005, Professor Gu Paihia of Shantou University College of Engineering worked hard to promote the CDIO engineering education model and carry out engineering education reforms. Pay attention to cultivating students' system engineering technical ability, implement advanced engineering education concepts, integrate the "professionalization" and "professional ethics" in my country's engineering education, and propose the EIP-CDIO training model [5], EIP (Ethics, Integrity, Professionalism), Strengthen project development capabilities, design capabilities and construction capabilities, and cultivate core qualities such as skills innovation capabilities, team collaboration capabilities [6], foreign language expression capabilities, and communication capabilities.

In order to better popularize the concept of CDIO engineering education, Shantou University and sister universities at home and abroad have carried out various forms of exchanges, seminars, promotion and training activities around CDIO with the support of education authorities. From January 8th to 9th, 2016, the "National CDIO Engineering Education Alliance" was established on the basis of the "Ministry of Education CDIO Engineering Education Reform Pilot Working Group". So far, a total of 105 universities in my country have joined the "CDIO Engineering Education Alliance".

\subsection{Research Goals and Problems to Be Solved}

CDIO stands for Conceive, Design, Implement and Operate. It is the latest achievement of internationally recognized engineering education reforms in recent years. It uses the entire life cycle of the product from conception and development to operation improvement, termination and disposal as a carrier to cultivate students' ability in engineering implementation, teamwork, communication, and large-scale system control. CDIO pays attention to practical teaching links and the cultivation of students' practical ability. It advocates that experimental teaching start from reality, then rise to theory, and finally return to actual operation, with the creation of final products and systems as the teaching purpose.

For the development and research summary of the CDIO model at home and abroad, combined with the actual situation of our country's engineering education, the inheritance and innovation of the CDIO education philosophy, in the assessment and evaluation system, no longer respect and rely on theoretical results, and pay more attention to the openness and innovation of students' thinking, Pay attention to the cultivation of students' values, sense of responsibility, attitudes and habits, as well as innovation ability, personal professional ability, communication and teamwork ability, explore more excellent experimental teaching system and put it into practice.

\section{Research Content and Objectives}

\subsection{The Connotation of the Digital Media Technology Experimental Teaching System Based on CDIO}

The school is committed to the training of applied and international talents [7]. The construction and practice of an integrated experimental teaching and management system based on the CDIO model is the starting point for the training of applied and international talents, exploring experimental teaching that can reflect advanced and scientific System and practice [8], embody the project-driven thinking, transplant the real engineering experiment environment into the curriculum, and complete the CDIO core competence training in experimental teaching. 
The experimental teaching system consists of seven aspects: laboratory operation mechanism, experimental teaching system construction, experimental teacher construction, laboratory management mechanism, open experimental teaching, virtualized laboratory, output mechanism and The evaluation mechanism is shown in Figure 1:

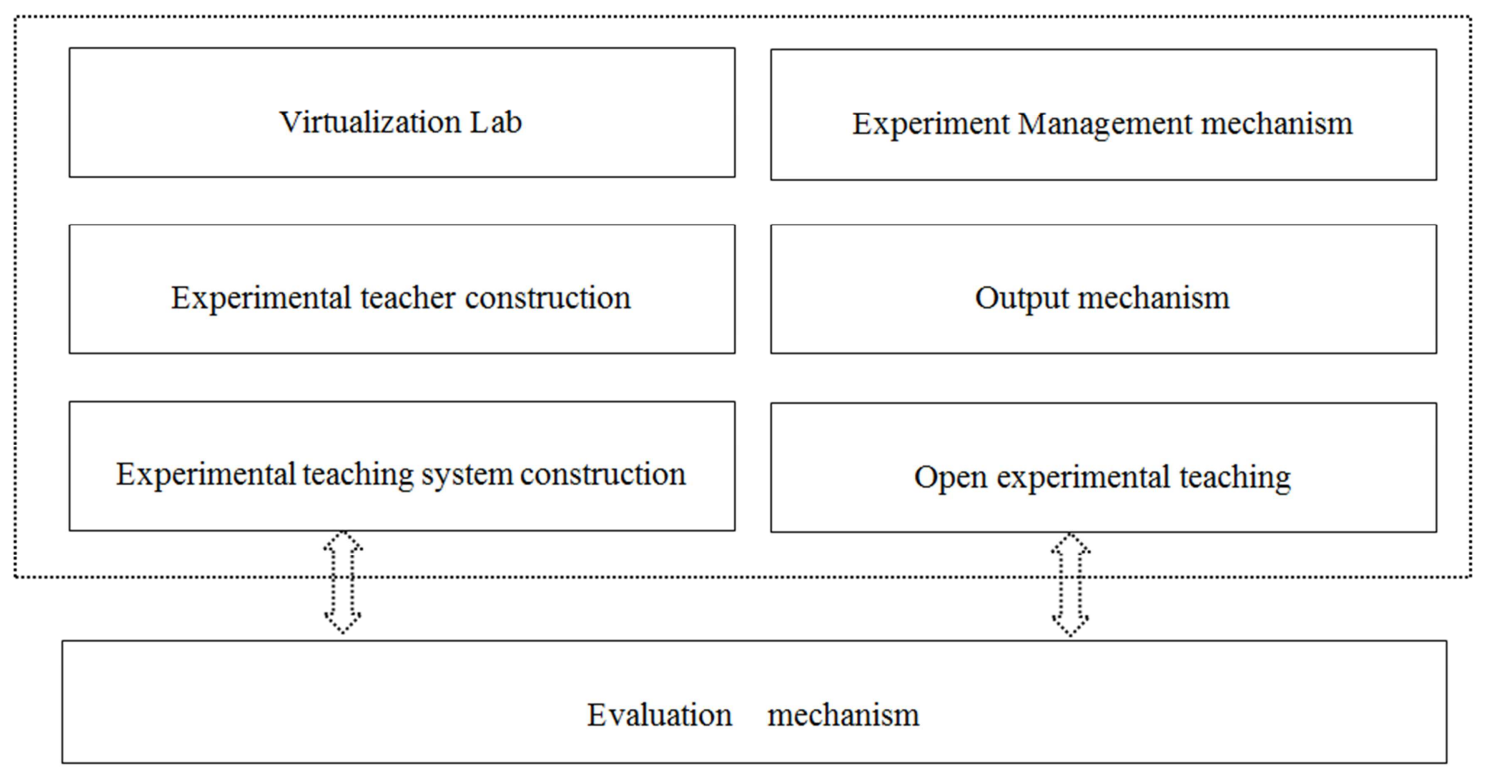

Figure 1. Experimental teaching system.

The digital media technology experimental teaching system is an important guarantee for the training of professional talents. The laboratory management mechanism is the center of the entire experimental teaching system and the foundation of the entire system through overall planning and overall coordination. The laboratory evaluation mechanism [9] can promote the optimization and improvement of the various modules of the entire system; the construction of experimental teachers is the soul of the entire system. No matter how good the organization is, people need to manage it, and no matter how scientific the system is, it also needs people to implement and experience, so the laboratory Teachers are the carrier for the construction and implementation of the experimental system. In the framework of the experimental teaching system, "people-oriented" is everywhere. The system is driven by CDIO model project teaching, organically combines theoretical teaching and experimental teaching, and promotes the overall development of students and adapts to social needs as the standard for talent training.

\subsection{Exploration of Experimental Teaching Mode of Digital Media Technology Based on CDIO Engineering Concept}

The establishment of CDIO experimental teaching mode is a subversion of the current experimental teaching system, and is based on the deep integration of CDIO engineering concepts. The experimental teaching mode takes the whole process of the product life cycle as the carrier [10], based on the real product industry platform environment to cultivate students' core abilities in engineering implementation, teamwork, and system control [11]. CDIO pays attention to practical teaching links and the cultivation of students' practical ability, advocating "from experiment to experiment".

In the process of experimental teaching, pay attention that the experimental curriculum should be consistent with the project teaching and professional talent training plan. The laboratory should be constructed according to the realization of the third-level project. At the same time, the construction of the experimental curriculum should also be oriented to the second-level project and the first-level project. It is nested and supports each other. The experimental teaching mode emphasizes the "reusability" of the laboratory [12], and the most direct manifestation of the reusability is the "modular" design of the laboratory. A single laboratory is regarded as an independent "module" and constitutes the most basic unit of the project [13]; the establishment of experimental projects above the second level must be selectively organized based on the existing laboratory functions, and the two support each other. If the laboratory group is compared to a "module" group [14], the project is like a work formed by combining "functional modules", and the use of the laboratory is arranged according to the project. as shown figure 2: 


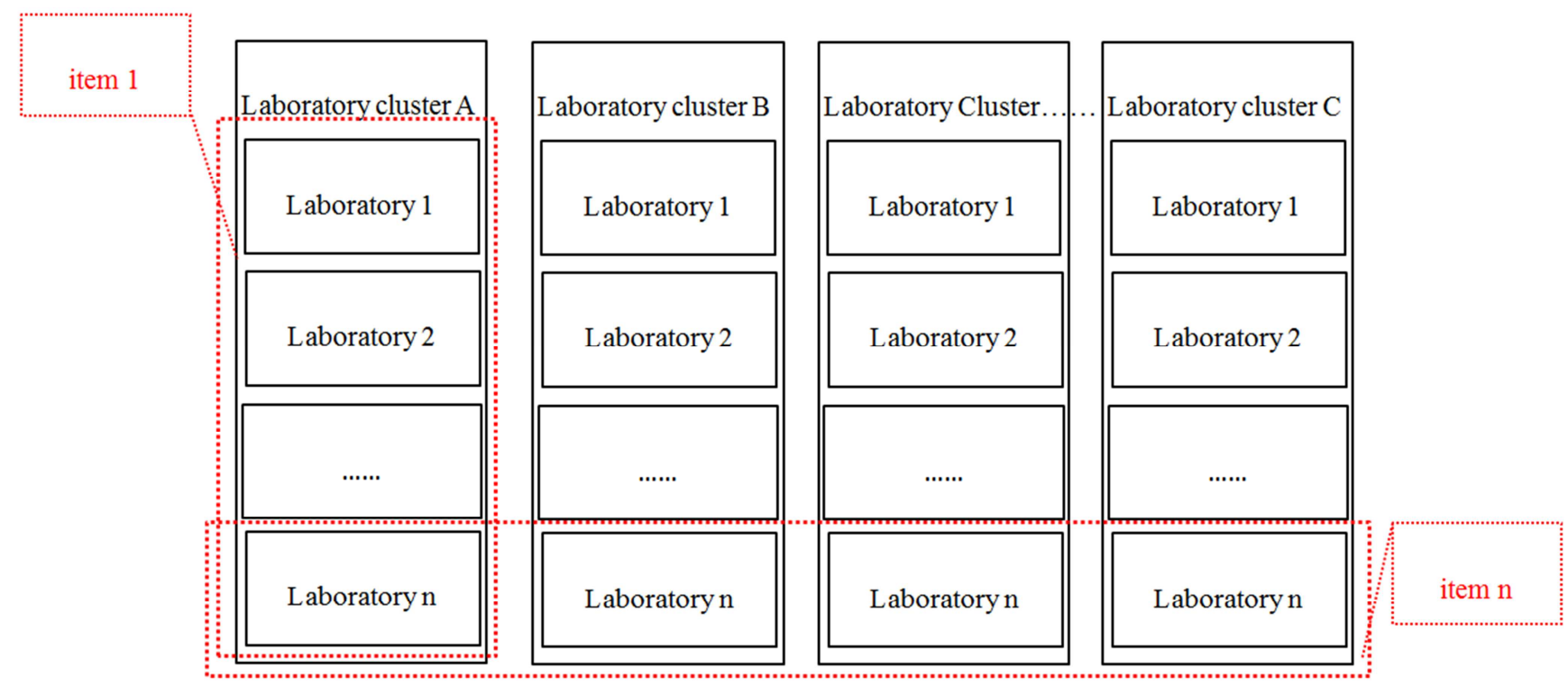

Figure 2. Laboratory cluster based on reuse.

\section{The Construction of the Curriculum Framework System Driven by "Smart Media Technology"}

\subsection{Background of Curriculum Framework System Construction}

Based on the new model of "new engineering" construction, deep integration of CDIO engineering concepts, construction of a "digital smart technology" [15] technology matrix, guided by the policies of the education authority, combined with national strategic deployments such as digital China and smart society, and persist in serving the digital media industry Combining with the local needs of Zhejiang to run a school, cultivate students' comprehensive ability in system design and planning of digital engineering architecture system, Internet big data analysis and mining, and digital intelligent management [16].

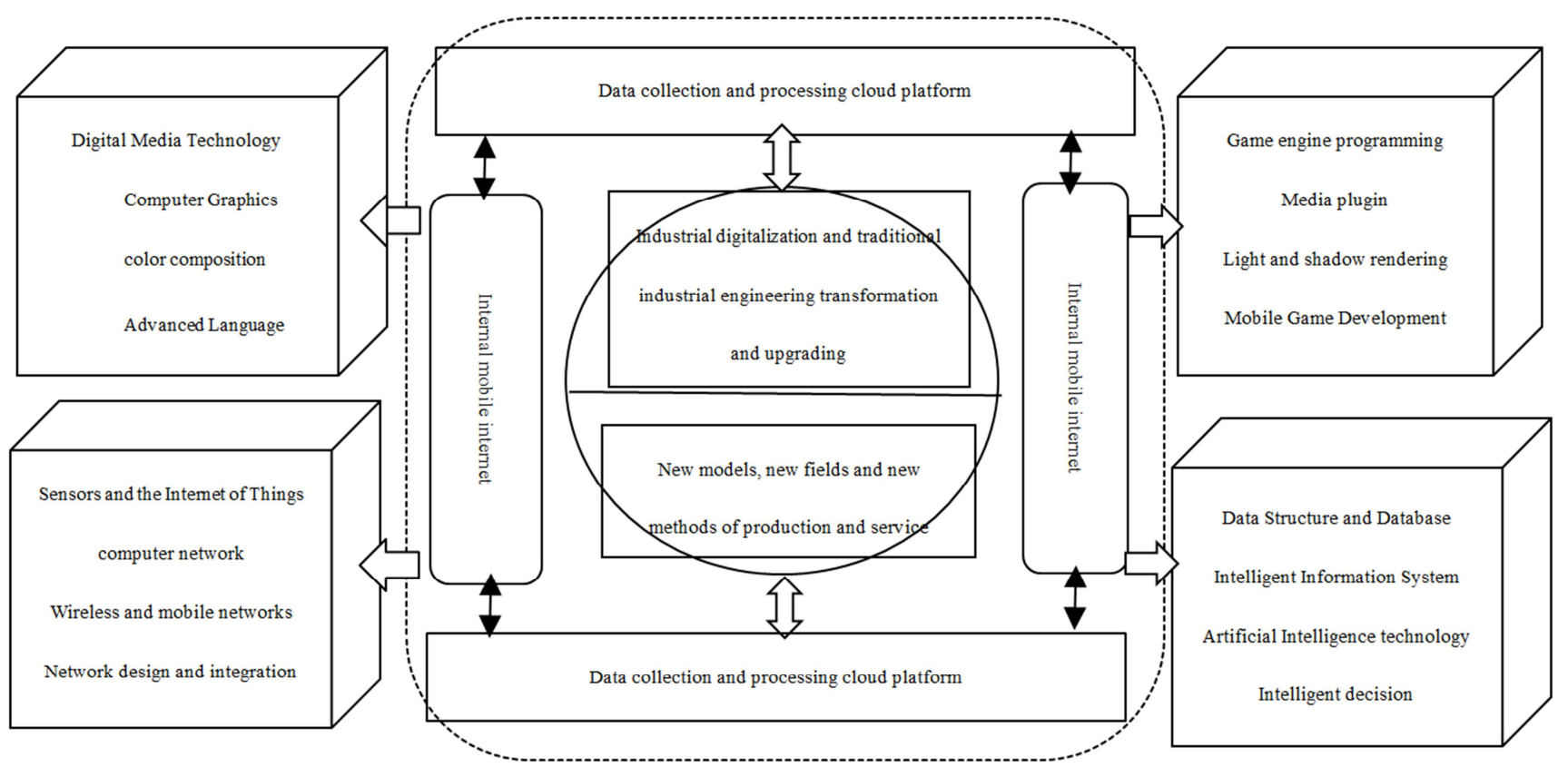

Figure 3. Intelligent Media Technology Curriculum Framework System

\subsection{The Main Body Construction of the Curriculum Framework System}

The construction of the curriculum system is based on the connotation of digital engineering, combined with the concept of CDIO engineering, with industrial digitization and digital industrialization as the direction, and on the premise of adhering to the training of CDIO core literacy, based on the 
system modularization idea [17], it is determined that the foundation of artificial intelligence, intelligent The "Intelligent Media Technology Curriculum Framework System" composed of four course modules of interconnected perception, digital modeling rendering and professional skills construction is shown in Figure 3.

The construction of the curriculum system is based on the integration of the knowledge structure of the curriculum system, blurs the boundaries of the curriculum itself, clarifies the teaching tasks based on the knowledge points, and builds a high-quality knowledge point system [18]. For example, data structure and algorithm courses focus on algorithm understanding, analysis, and basic principles and theoretical cognition, high-level language programming courses emphasize algorithms from principle level understanding to realization, and computer graphics is on data structure and high-level language programming. Comprehensive application; Finally, artificial intelligence and machine learning courses combine various classic algorithms and current popular applications, based on social economic activities or technical requirements, to form a closed loop from theoretical knowledge learning to application practical operations.

\subsubsection{Construction of Teaching Staff}

In the construction of the faculty, we pay attention to the concept and teaching of CDIO engineering, especially the requirements of new engineering construction in the construction and implementation of the experimental teaching system, forming two teaching and research teams of "Smart Media Data Visualization" and "Smart Media Technology Innovation", inviting well-known industry When algorithm engineers and product managers participate in the teaching process of part of the professional courses, strengthen practical projects to stimulate teachers' scientific research and vocational skills training, establish industry-university-research cooperation demonstration bases, promote the digital transformation of the industry, and use industry cases to improve talent training Project implementation ability [19].

\subsubsection{Practice Ability Training}

For the training of professional talents in digital media technology, the first is the "Smart Media Technology Laboratory-University Student Internship Unit" as the base, which integrates professional core courses and graduation design, and uses the advantages of equipment such as the "Smart Media Technology" laboratory and 3D printing workshops., To enhance students' engineering practice ability.

In general, the high-quality practice resource base is updated, the hardware training platform is upgraded, and the industry mentors are added to dynamically match the goals of talent training. At the same time, professional core courses, excellent corporate project cases, algorithm engineers, and social practice units are integrated to improve all aspects Practice training of professionals in digital media technology.

\section{Practice of Experimental Teaching System Based on CDIO Mode}

\subsection{Strengthen Basic Experimental Teaching}

Strengthen students' basic professional skills, optimize experimental teaching cases, and adjust the ratio of experimental and theoretical teaching hours. Through this level of experimental teaching, students can master the basic experimental methods of digital media technology in a solid and systematic manner, cultivate the conversion of students' professional knowledge to vocational skills, and cultivate students' desire for professional improvement [20].

\subsection{Design of Comprehensive Experimental Teaching System}

The goal of the experimental teaching system design is to improve students' comprehensive use of computer technology, data visualization technology, and data mining technology to cultivate students' innovative spirit, and to divide the experimental teaching of digital media technology through the establishment of a highly simulated experimental media platform inside and outside the school. More than ten professional experimental courses with overly detailed and repeated experimental content are organically integrated into a comprehensive experimental teaching module to cultivate students' comprehensive ability to fully meet the needs of digital media technology talents.

\subsubsection{Stratified, Classified and Advanced Teaching Methods to Consolidate Students' Basic Knowledge and Skills}

Experimental teaching has the characteristics of "large quantity and wide range". It not only offers basic computer experimental courses, but also provides professional experimental courses and innovative practice courses, and also provides an experimental environment for students' innovation and entrepreneurship projects. According to the training requirements of students at different levels, experimental teaching is arranged in levels, categories, and progressive, and a three-level modular and advanced experimental course teaching system based on basic level, professional level and innovation level has been constructed. [21].

\subsubsection{Networked and Open Teaching Methods, Combining Virtual and Real, Promote Students' Professional Practical Ability}

Carry out the CDIO project model, in which the network teaching platform is used to provide downloading experimental teaching resources and students' experimental homework submission, and can also be used for innovative training teaching and technology competitions. In addition, actively build an online education platform and explore advanced evaluation teaching. Various experimental teaching resources are fully open to students of "time, space, content and resources" [22], to enhance students' autonomy and initiative in learning, and to cultivate students' scientific research ability and innovative practice ability. 


\subsubsection{The Teaching Methods of Scientific Research Feeding Back Teaching, and Increase the Update Rate of Experimental Projects}

Make full use of the scientific research advantages of the School of Computer Science and the scientific research capabilities of cooperative enterprises [23] to promote the integration of scientific research and experimental teaching. Encourage self-developed experimental equipment, encourage teachers to use actual scientific research topics as experimental projects, guide students to combine learning and research, and cultivate students' scientific research awareness and innovative spirit. In the actual teaching process, discussion-based interactive teaching methods and research project-driven teaching methods are mainly used.

\subsubsection{School-enterprise Cooperation, Enterprise Practical Teaching Methods, Cultivate Students' Innovation and Entrepreneurial Ability}

It mainly includes two categories. One is to conduct experimental teaching through the "simulated enterprise" [24] in the school. Students in the "simulated enterprise" strictly follow the "enterprise" model for work, attendance, and performance appraisal. They must complete daily work logs. Through the practical training work of "simulated enterprise", students' overall quality, comprehensive ability and employment competitiveness can be cultivated. The other is the practical teaching of off-campus business practice bases cooperating with the center, making full use of the unique business practice bases, so that students can get effective training and knowledge in internships, and students can also get full engineering practice opportunities., Enhance the ability to adapt to the social environment.

\section{Conclusion}

The CDIO engineering concept is deeply integrated with the construction of the experimental teaching system, taking students' practical ability and teamwork ability as the ultimate goal of the construction of the experimental teaching system. The experimental teaching system emphasizes the organic combination of knowledge points in experimental courses, builds a green ecological circle of experimental teaching, and enhances the competitiveness of talent training under the background of "internationalization".

\subsection{The Goal of Reshaping the Experimental Teaching System}

Starting from the fundamental tasks of the laboratory and its teaching, the system sorts out and straighten out the relationship between the laboratory and its teaching links; starting from the integrated height and vision, it establishes a four-in-one experimental teaching and management core; Continuous optimization from the perspective of continuous improvement, the introduction of a dynamic, self-learning, and self-adjusting evaluation mechanism; starting from the goal of internationalization, practicality, and individual talent training, a virtual, open and income-generating system has been established. Laboratory mechanism. The system fully considers the characteristics of mass education and elite education, and integrates theoretical teaching and experimental teaching with CDIO model project teaching as the main line, which stimulates students' interest in independent learning, and promotes students' overall development and adapts to social needs. The fundamental standard to measure the level of talent training.

\subsection{Promote the Organic Integration of Experimental Teaching and Theoretical Teaching}

Experimental teaching and theoretical teaching complement each other. Compared with theoretical teaching, experimental teaching is intuitive, comprehensive and innovative. Experimental teaching is not only an extension and expansion of theoretical teaching in the classroom, it should be more of an independent system, just like a person's "two legs", complementary to theoretical teaching, and a combination of knowledge and practical ability. Taking the experimental teaching system construction of the data visualization course group as a starting point, the construction practice and discussion of the experimental course system are carried out.

\section{Fund Project}

Zhe Jiang province Educational Science Plan 2020 (university) Research Project," Construction and Practice of Experimental Teaching and Management System Based on CDIO Model" (2020SCG357).

\section{References}

[1] Teaching reform and practice of "Basic Industrial Engineering" based on CDIO [J]. Ge Xiaomei. Gao Xuemei. 2018 (20).

[2] Research on the Comprehensive Training Innovation Model of Industrial Engineering Specialty Based on CDIO [J]. Qi Lixia. Education Modernization. 2017 (35).

[3] From the ability outline to the CDIO model of integrated curriculum system design - One of the series of reports on the innovative education experimental zone of Beijing Jiaotong University [J]. Cha Jianzhong, Xu Wensheng, Gu Xueyong, Zhu Xiaomin, Lu Yiping, E Mingcheng. Higher Engineering Education Research. 2013 (02).

[4] Diversified teaching mode and evaluation of engineering basic courses-taking engineering thermodynamics teaching practice as an example [J]. Yu Juan. Research in Higher Engineering Education. 2017 (04).

[5] AHP quantitative method for performance appraisal of personnel in experimental teaching center [J]. Yang Fengkai, Cheng Suxia. Experimental Technology and Management, 2018, 35 (5): 229-232.

[6] Exploration of college physics experiment teaching system based on OBE concept [J]. Wu Lihua, Liu Zhihai, Zhang Yang, Li Ping, Wang Liyuan, Li Song. Experimental Technology and Management. 2018 (10). 
[7] Research on laboratory construction model based on "Internet $+"$ [J]. Hong Wenzhen, Lan Xinbo. Experiment Science and Technology. 2018 (02).

[8] [United States] Crowley. Re-understanding engineering education: International CDIO training model and method [M]. Translated by Gu Peihua, Shen Minfen, Lu Xiaohua. Beijing: Higher Education Press, 2009.

[9] CDIO-based experimental teaching reform of computer science [J]. Guo Jiao, Yan Pei, Ying Hong, etc. Experimental Technology and Management, 2011 (2).

[10] Thinking about the key abilities of engineering talents from the perspective of "new engineering"[J]. Wu Tao, Liu Nan, Sun Kai. Heilongjiang Higher Education Research. 2018 (03).

[11] Discussion on experimental teaching reform under the background of "new engineering" [J]. Wang Chengxin, $\mathrm{Xu}$ Longjun, Zhang Tianwei. Higher Architectural Education. $2019(02)$

[12] Construction and Practice of National Experimental Teaching Demonstration Center under the Background of "New Engineering" $[\mathrm{J}]$. Wang Baojian, Wang Yongquan, Duan Yugang, Chen Xuefeng. Research in Higher Engineering Education. 2018 (06).

[13] Inquiry into the cultivation of talents in colleges and universities under the background of "new engineering" construction $[\mathrm{J}]$. Li Huiqin. Quality Education in Western China. 2018 (12).

[14] The reform of the four-in-one practice teaching system of "learning, practicing, researching and creating" under the background of new engineering disciplines [J]. Dai Yahong, Li Hong, Wu Yangbo, Chen Fen. Experimental technology and management. 2017 (12).

[15] Thoughts on the path of construction and development of new engineering disciplines [J]. Lu Guodong, Li Tuoyu. Research on Higher Engineering Education. 2017 (03).

[16] Accelerate the development and construction of new engineering disciplines, actively adapt to and lead the new economy [J]. Wu Aihua, Hou Yongfeng, Yang Qiubo, Hao Jie. Research on Higher Engineering Education. 2017 (01) Object-oriented programming based on the CDIO model Exploration and Practice of Curriculum Design Reform [J]. Zhu Hongmei, Sun Wei, Zhang Guangmei, Li Weiyan, Li Bin. China Modern Educational Equipment. 2019 (23).
[17] Lin Jian. Facing the future of China's new engineering construction [J]. Educational Research of Tsinghua University, 2017, 38 (2): 26-35.

[18] Xia Jianguo, Zhao Jun. Discussion on the reform and development of engineering education in local colleges and universities under the background of the construction of new engineering subjects [J]. Higher Engineering Education Research, 2017 (3): 15-19, 61.

[19] Exploration of Performance Evaluation of University Laboratory Managers [J]. Shen Shunan, Huang Gang, Lu Zifang, et al. Laboratory Research and Exploration, 2017, 36 (11): 242-245, 282

[20] Exploration of New Engineering Talents Training Model-Based on the Perspective of Collaborative Innovation Center Construction [J]. Wang Peiliang, Li Bing, Wang Rongde, Qian Yi, Du Shuxin. China University Science and Technology. 2018 (03).

[21] Construction and Practice of Pharmaceutical Engineering Practice Teaching System Covering Complex Engineering Problems [J]. Li Hui, Gong Jinsong, Xu Zhenghong, Shi Jinsong. University Laboratory Science and Technology. 2019 (04).

[22] Research on the cultivation of innovative talents in the engineering training center under the background of new engineering disciplines [J]. Ye Xiaoqin. Experimental Technology and Management. 2019 (12).

[23] Office of the deputy assistant secretary of the army: Emerging Science and Technology Trends: 2016-2045, 2016. Higher Education (ICSSHE-19) [C]. 2019.

[24] Research on Intelligent Logistics Talent Cultivation in Emerging Engineering Construction [A]. Ge Dong-yuan, Wei Jian-jun, Luo Hui-cong, Luo Hai-ping, Liang Shuang-yi. Advances in Social Science, Education and Humanities Research, Volume 176 [C]. 2018.

\section{Biography}

Jiangtao Wang (1980-), male, Wendeng District, Weihai City, Shandong Province, master, associate professor, Director of the Network Communication Experimental Teaching Center, Engaged in Computer Vision, Laboratory Construction And Management. 